\title{
MATERIALITY ANALYSIS IN SUSTAINABILITY REPORTING: A TOOL FOR DIRECTING CORPORATE SUSTAINABILITY TOWARDS EMERGING ECONOMIC, ENVIRONMENTAL AND SOCIAL OPPORTUNITIES
}

\author{
Armando CALABRESE ${ }^{1}$, Roberta COSTA ${ }^{2 *}$, \\ Nathan LEVIALDI GHIRON ${ }^{3}$, Tamara MENICHINI ${ }^{4}$ \\ ${ }^{1,2,3}$ Department of Enterprise Engineering, University of Rome "Tor Vergata", \\ Via del Politecnico 1, 00133, Rome, Italy \\ ${ }^{4}$ Industrial and Mechanical Engineering, University of Rome "Niccolò Cusano", \\ Via Don Carlo Gnocchi 3, 00166, Rome, Italy
}

Received 04 October 2018; accepted 26 April 2019

\begin{abstract}
Materiality analysis is a multi-purpose tool for prioritising sustainability issues from the double perspective of companies and stakeholders, meaning that both parties contribute to identifying the present and emerging social and environmental risks and opportunities. The current study proposes a practical and structured approach for performing materiality analysis, integrating the well-known Global Reporting Initiative (GRI) materiality matrix and a new "adequacy matrix". The purpose of the GRI materiality matrix is to prioritize sustainability issues in terms of relevance to both companies and stakeholders. The adequacy matrix supports evaluation of the transparency and effectiveness of corporate sustainability (CS) communication.

Particularly, the paper aims to give indications to companies that want to prepare a sustainability report according to the GRI guidelines by planning the allocation of resources to reporting activities: the comparison between the positioning of GRI sustainability aspects in the two matrices serves in identifying the most critical issues for improving accountability. The proposed method includes a consistency test, to overcome the subjectivity, uncertainty and vagueness affecting judgements. The results provide managers with useful information for aligning CS strategic decision-making, sustainability reporting, and accountability to stakeholders. An illustrative application to a small and medium-sized (SME) company completes the paper.
\end{abstract}

Keywords: materiality analysis, sustainability reporting, sustainability strategy, sustainability performance, Global Reporting Initiative (GRI) guidelines.

JEL Classification: Q51, Q56. 


\section{Introduction}

In order to win at sustainable development, companies must change from the approach of regulatory compliance to a different vision of sustainability as an opportunity for innovation and value generation. Companies must integrate sustainability in strategic decision-making, based on the identification of emerging opportunities and threats in the social and environmental spheres (Calabrese, Costa, Levialdi, \& Menichini, 2019; Forstater et al., 2006). In fact, Salzmann, Ionescu-Somers, and Steger (2005) define corporate sustainability (CS) "a strategic and profit-driven corporate response to environmental and social issues", determined in relation to the organization's activities.

Progress in the economic, environmental and social spheres must go hand in hand, in anticipation and response to the continually changing global context. CS must therefore evolve from simple impact management of business activities to the creation of shared value, achieving benefits to both the company and overall society (Porter \& Kramer, 2006). Recognizing this, some companies have accepted that they must identify the sustainability issues that are most material to their stakeholders, and consider their expectations in the formulation of strategies and in corporate reporting (Font, Guix, \& Bonilla-Priego, 2016). In adopting this approach, companies can serve the interests of a widening group of stakeholders and increase the creation of shared value (Harrison \& Wicks, 2013).

Materiality analysis is therefore fundamental to CS, and in particular, to the creation of shared value, since it provides the necessarily integrated approach to both the definition of sustainability strategies and to reporting (Whitehead, 2017). Materiality analysis serves in evaluating the relevance of the economic, environmental, and social issues, and ensures that sustainability strategies and reporting address those that pose significant risks and opportunities to the company business and to its stakeholders (Font et al., 2016). Indeed, the principle of materiality aims at guiding decision makers to identify and to be clear about sustainability issues that matter (AccountAbility [AA], 2018). With this regard, organizations regardless of size can benefit from using open-source accounting standards such as AA standards and Global Reporting Initiative (GRI) guidelines that aim at supporting companies to transparently account to stakeholders on sustainability issues that matters to them (AA, 2015; Global Reporting Initiative [GRI], 2013a, 2013b). Particularly, GRI guidelines are useful for companies that engage in sustainability reporting as they provide support for structured sustainability reports. Moreover, unlike other sustainability reporting standards, GRI guidelines focus on a multi-stakeholder approach to materiality analysis (Landrum \& Ohsowski, 2018).

Materiality analysis requires the company to engage with different groups of stakeholders, gathering their insights on specific economic, environmental, and social issues. These insights assist in identifying not only what the company should report on, but also how the strategies for sustainability should respond to continually changing economic, social and environmental circumstances (Forstater et al., 2006). To this purpose, GRI guidelines define a framework of sustainability aspects that describes the economic, environmental, and social dimensions of the sustainability performance. Within the standardized categories and subcategories of aspects, the GRI framework allows each company the flexibility to report on issues of most relevance for the company and its stakeholders (Landrum \& Ohsowski, 2018). Moreover, a 
materiality matrix approach is proposed with the aim to prioritize sustainability issues in terms of two dimensions: the degree of stakeholder interest and the importance of the issue to the company in terms of potential business impact (GRI, 2016, 2013a).

On this regard, the GRI guidelines explicitly encourage the involvement of stakeholder groups in materiality analysis, in order to identify and prioritize sustainability issues. Nevertheless, the scientific literature has paid little attention to the practical application of stakeholder participation (Pérez-López, Moreno-Romero, \& Barkemeyer, 2015). For instance, a problem not sufficiently addressed is that of discrepancies in judgements, due to subjectivity and uncertainty. Most companies have many types of stakeholders characterized by conflicting interests, expectations, and values (AA, 2015), thus making subjectivity a critical aspect of the materiality assessment. Given the complexity of sustainability issues, some contradictions could emerge during the assessment procedure, making stakeholder judgments inconsistent (Calabrese, Costa, Levialdi, \& Menichini, 2016). Only a few studies have investigated the potential of quantitative methods in addressing this problem, and more generally as a support to materiality analysis (e.g. Bellantuono, Pontrandolfo, \& Scozzi, 2016). Given this observed lack of research into practical and quantitative approaches, this study proposes a method for the application of materiality analysis, based on the use of an "adequacy matrix", in conjunction with the well-known GRI materiality matrix. The GRI materiality matrix maps sustainability aspects in terms of relevance to both companies and stakeholders, while the adequacy matrix evaluates the effectiveness of their CS communication. Therefore, the comparison between the positioning of the sustainability aspects in the two matrices provides guidance on effective allocation of resources in the reporting activities. The method should be helpful to SMEs for properly focusing reporting activities on the "material" aspects that are not adequately communicated, thus overcoming the time and financial constraints that SMEs often meet in sustainability reporting (Baumann-Pauly, Wickert, Spence, \& Scherer, 2013). The paper proceeds with a review of the relevant literature on materiality. Section 2 describes the steps of the "zone matrices" method and provides an illustrative example of application to an SME operating in the water technology sector. Last Section presents the conclusions and discussion.

\section{Materiality in sustainability reporting}

The concept of materiality derives from financial reporting. The principle is that audit practices must filter and guarantee information in a manner that ensures true, fair and useful representation of the company's financial situation, in support of capital protection, risk management and decision making (Edgley, 2014; Messier, Martinov-Bennie, \& Eilifsen, 2005). More recently, the concept of materiality has been adapted to sustainability reporting. In this area, the principle is that information must be filtered and guaranteed in support of those company activities and decisions impacting on society and the environment, and affecting present and future stakeholder needs (Hahn \& Kühnen, 2013). In the GRI guidelines, widely accepted standard for sustainability reporting (Calace, 2016), "material aspects" are those that reflect the company's significant economic, environmental and social impacts, or those which significantly influence stakeholders' assessments and decisions (GRI, 2016, 2013a, 2013b). 
Besides, materiality analysis is the process through which a company systematically identifies, selects, prioritizes and reviews what is material to the company and its stakeholders, and thus merits inclusion in sustainability reports (GRI, 2013a, 2013b).

Materiality analysis is conceived as a systematic and rigorous process, contributing to the identification of significant, stakeholder-oriented metrics of CS. Such metrics can assist the company in enhancing awareness of sustainability performance, in improving the quality of reporting and its readability for different actors (Carpejani, Pinheiro de Lima, Gouvea da Costa, Machado, \& Da Veiga, 2017; Russo-Spena, Tregua, \& De Chiara, 2016). They assist in benchmarking, and in initiatives for stakeholder engagement (Forstater et al., 2006). According to Font et al. (2016), materiality analysis can in fact serve in redirecting CS and its reporting towards greater inclusion of stakeholder needs, and in facilitating the creation of shared value, since it identifies the issues with the highest potential to benefit both the company and its stakeholders. When sustainability reports deal with material issues, they reveal $\mathrm{CS}$ as a driver of innovation and economic growth, disclosing the inputs for managing the future (Bowers, 2010).

Thanks to materiality analysis, companies can improve their accountability to stakeholders and make sustainability efforts more effective. Indeed, a materiality analysis approach to sustainability reporting allows dealing with fundamental theoretical concerns such as: subjectivity in assessment and consistency of judgements; complexity and uncertainty of sustainability issues; the need to meet different stakeholders' expectations; balancing between standardized assessment procedures (that ensures comparability of reporting) and the need to take into account the specificity of different contexts (Ascough, Maier, Ravalico, \& Strudley, 2008; Greenwood, 2007; Manetti, 2011; Zhou, 2011).

Nevertheless, materiality analysis presents criticalities that limit its practical use in companies (Calabrese, Costa, Ghiron, \& Menichini, 2017). The process of assessing materiality requires companies to consider the strategic value of the opportunities and risks related to the various aspects of sustainability. This means considering how much the company's impacts are crucial to the company's performance, to its ability to grow and obtain competitive advantage (GRI, 2013b).

The involvement of stakeholders in materiality analysis serves to achieve more fair and complete representation of the company conduct (Crane \& Livesey, 2003; Unerman, 2007). Indeed the ISO 26000 standard on social responsibility stresses the importance of disclosing company sustainability issues to stakeholders (International Organization for Standardization [ISO], 2010), and the GRI guidelines recommend that stakeholders' expectations be considered as key reference points for decisions in the preparation of reporting (GRI, 2013a). Stakeholders should be asked to evaluate the company response regarding each sustainability aspect, and the transparency of the relative reporting (GRI, 2013b). In particular, sustainability reporting should include issues that are currently emerging as important, whether in terms of impacts on company strategy or only of stakeholder expectations (GRI, 2013b).

On this regard, the principle of stakeholder inclusiveness consists in identifying the interested parties and allowing them to participate in the definition of the material sustainability aspects of an organization, especially emerging ones (AA, 2018). In fact, it is important to consider that most companies have many types of stakeholders characterized by conflicting 
interests, which influence the organization and are influenced by it (AA, 2018). Moreover, materiality is often "stakeholder specific", meaning that some aspects are material to some stakeholders but not to others (AA, 2015). An inclusive organization is able to identify its main stakeholders and their respective views and interests, and how they can influence decisions on sustainability (GRI, 2013b). In addition, companies should not use stakeholder engagement to mitigate or manage stakeholders' expectations, but to create a relationship of mutual responsibility and collaboration (Andriof, Waddock, Husted, \& Rahman, 2017). In this way, stakeholders participate in CS management by highlighting problems deemed relevant because generate positive or negative impacts on companies and overall society (Manetti, 2011).

The GRI guidelines propose a "materiality matrix" approach to determining materiality thresholds and ordering sustainability aspects, according to their importance to stakeholders and in terms of company economic, environmental, and social impacts. The relative priority levels should then be reflected in the level of detail or "coverage" in the reporting of sustainability aspects. The GRI guidelines stress the assessment process must be systematic, documented and replicable; however, the guidelines, including the materiality matrix, do not provide any true operational guidance for calculating the priorities of different aspects, or for setting materiality thresholds which would identify if an aspect is sufficiently significant to be included in the report.

In fact, materiality analysis remains a highly subjective process, in which personal opinions, experiences and expectations are key to assessing the significance of sustainability aspects (Zhou, 2011). Real-world decision-making involving such subjective judgements is typically influenced by uncertainty and vagueness (Yan \& Ma, 2015; Costa \& Menichini, 2013). New methods are therefore needed to effectively represent and deal with the complexity and uncertainty involved in stakeholder perceptions, as these are incorporated in materiality analysis and affect the quality of sustainability reporting (Ascough et al., 2008; Manetti, 2011). Stakeholder views could be diverse and conflicting, depending on their different interests and expectations (AA, 2015), thus making subjectivity assessment a critical aspect of the materiality analysis (Calabrese et al., 2016).

To date, few contributions have proposed a structured approach for materiality analysis, through which stakeholders can participate directly in defining the reporting content (Bellantuono et al., 2016; Hsu, Lee, \& Chao, 2013). Moreover, some authors (e.g. Jones, Comfort, \& Hillier, 2016; Guix, Bonilla-Priego, \& Font, 2018) evidenced the difficulties faced by organizations in employing the materiality matrix, coherently with the content of their report and the qualitative or quantitative assessment of material issues. None of these studies have considered the need to evaluate the adequacy, effectiveness and transparency of the sustainability reporting.

Based on a review of the prior contributions, Calabrese et al. (2017) list the necessary characteristics for a new materiality analysis method, providing effective inclusion and representation of stakeholder perceptions. Companies should adopt a constructive and participatory assessment approach, aimed at mediating potential conflicts and differences between stakeholders' opinions (Bellantuono et al., 2016; Elias, Jackson, \& Cavana, 2004). Moreover, the consistency of the opinions expressed should be tested, to avoid or mitigate contradic- 
tions in judgments (Alonso \& Lamata, 2006). The method should propose a quantitative, structured, and repeatable approach for determining the relative priorities for reporting different sustainability aspects, and for setting materiality thresholds. Finally, the method should provide very practical guidance on how to ensure comparability of results, set threshold values for reporting on the different aspects, and for determining the information to be included on the basis of its level of materiality. Taking into account both the background literature and these specific recommendations, this study proposes the zone matrices method that is described by means of its practical application to an SME.

\section{2. "Zone matrices" for materiality analysis: an illustrative application}

The zone matrices method combines materiality analysis to the "adequacy" assessment of CS communication practices, such as sustainability reports. Here the term "adequacy" refers to the capacity of the company's communication about CS to provide stakeholders with transparent and useful information, capable of supporting their assessments and decisions. To this end, the method introduces an "adequacy matrix", and proposes its use in conjunction with the GRI materiality matrix.

The zones of the two matrices serve in prioritizing the sustainability aspects by strategic importance, and in terms of adequacy of the relative CS communication as perceived by stakeholders. In particular, the comparison between the positions of the sustainability aspects in the two matrices makes it possible to identify the most critical sustainability issues, thus planning the allocation of resources to future reporting or CS communication activities. The adequacy assessment of CS communication practices concerns sustainability reports, but it could also involve other forms of CS communication, such as company websites, certifications, product labelling, press coverage, advertising, blogs, social media pages, etc. Indeed, the evolving communication landscape, where the web has become one of the predominant communication channel for sustainability initiatives, is reshaping CS communication and effective stakeholder engagement (Nwagbara \& Reid, 2013; Lindgreen \& Swaen, 2010), and companies should use appropriate communication channels to communicate to different stakeholders their sustainability practices (Da Giau et al., 2016; Silvestre, Antunes, \& Leal Filho, 2018).

For the sake of brevity and clarity, the zone matrices method of materiality analysis is presented by means of its application to an Italian SME operating in the design and manufacture of water technology components and wastewater treatment systems. The company, called ACMO, provides a useful illustrative example, primarily because of the importance of water technology industries in human health and environmental protection (Byrne, Lohman, Cook, Peters, \& Guest, 2017). Moreover, ACMO operates in a business sector with high environmental, economic and social impacts (Muga \& Mihelcic, 2008; Mahgoub, van der Steen, Abu-Zeid, \& Vairavamoorthy, 2010; Hellström, Jeppsson, \& Kärrman, 2000). ACMO is certified under ISO 14001 (Environmental Management Systems Standard) and ISO 9001 (Quality Management Systems Standard), indicating that it is committed to sustainability. In addition, the board of directors is interested in making sustainability an integral part of the company strategy and business processes (Calabrese et al., 2019). Consequently, ACMO is a 
good choice as an illustrative example because it is oriented to sustainability, and it intends to further improve accountability by developing an annual sustainability report as a supplement to its existing CS communication practices (e.g. company website, reporting in mass media and business publications, and through social media and trade fairs). In addition, ACMO management has been collaborating with the authors for three years, embarking on a path of sustainable development.

\section{Step 1: Identifying what stakeholders to involve}

Thanks to materiality analysis, companies have the possibility to meet stakeholders' expectations about the company's actions and response to sustainability issues (GRI, 2013b). The materiality analysis begins with the identification of those stakeholders whose participation in the materiality evaluation process would be useful.

According to GRI (2013a, 2013b), the materiality of sustainability aspects (Table 1) should be assessed from the two perspectives of: their "influence on stakeholder assessments and decisions", and relative to their "significance of organization's economic, environmental and social impacts". The aim of the "stakeholder influence" perspective is to prioritize the GRI aspects according to "the expectations of stakeholders regarding action and response to an aspect" (GRI, 2013b, p. 36). The aim of the "organization impacts" perspective is to prioritize aspects according to "their influence on the organization's ability to deliver on its vision and strategy" (GRI, 2013b, p. 36). The proposed method therefore identifies two groups of stakeholders, classified as to whether their influence on the organization's strategic decisions and actions is "direct" or "indirect". The first group (hereafter "decision makers") is comprised of senior executives with direct responsibility for setting corporate strategy, as well as middle and line managers responsible for strategy implementation (Dwyer, Richard, \& Chadwick, 2003). The second group (hereafter "stakeholders") is comprised of other employees, clients, suppliers, the local community and other external parties. The involvement of "decision makers" allows companies to take into consideration also those sustainability impacts that "stakeholders" could not recognize, as they could occur far from their sphere of influence and interest (GRI, 2013b).

The GRI evaluation perspectives of "organization impacts" and "stakeholder influence" serve in defining the two dimensions of the "materiality matrix". Thus, those stakeholders with direct influence on strategic decisions will be asked to evaluate GRI aspects in terms of importance to the organization (axis $\mathrm{x}$ of the materiality matrix), while those with indirect influence will be asked to evaluate the importance to stakeholders (axis y of the materiality matrix). Similarly, the adequacy matrix is again defined in terms of adequacy as judged by stakeholders with direct influence ( $\mathrm{x}$-axis), and with indirect influence (y-axis).

The selection criterion of stakeholders should be based on their representativeness of stakeholder categories (e.g. clients, employees, etc.) and their capability to offer relevant information on sustainability topics (Manetti, 2011). Moreover, stakeholder selection can be drawn from existing and ongoing engagement mechanisms, as well as from ones specifically launched to define the content of the sustainability report (GRI, 2013b). In this way, stakeholders participate in company decision-making by underlining sustainability problems and, thus, influencing management decisions on sustainability (Andriof et al., 2017). 
The analysis of the organizational chart and various interviews with top-managers allow identifying stakeholders with direct influence on strategic decisions. In the ACMO case the "decision makers" were: the chairperson of the board of directors, the CEO, the production manager, the design manager and the quality system manager.

The stakeholders with indirect influence on strategic decisions should be selected involving stakeholder representatives that "have dialogue" with management (Manetti, 2011). Basing on the previous considerations, the selected ACMO "stakeholders" were: four employees, a strategic supplier, one of the main customers, and the mayor of the city hosting the company headquarters and main production (as representative of the local community). The employees, the customer and the supplier were chosen as key representatives of their stakeholder categories, as spokespersons of their expectations and interests. All these stakeholders have been involved in the materiality analysis, as illustrated in the steps below.

ACMO has not yet published periodic sustainability reports, so the evaluation of disclosure adequacy was conducted by referring to other forms of CS communication, conducted through the company website, reporting in mass media and business publications, and through advertising and trade fairs.

\section{Step 2: Selection of relevant sustainability aspects}

The aim of the second step is to define the set of relevant sustainability aspects to which apply the zone matrices method, as detailed in the following steps. The standardized framework of GRI sustainability aspects ensures a Triple Bottom Line (TBL) approach to accountability as it allows a full accountability on the company-stakeholder relationship, company-environment interactions and economic and financial performance (Milne \& Gray, 2013; Stenzel, 2010). However, not all the sustainability issues have the same relevance for every company (ISO, 2010); therefore, companies are asked to identify the applicable sustainability aspects among those proposed by GRI under each TBL dimension (Table 1).

If the company considers a sustainability aspect as "not applicable", this aspect should be excluded from the analysis and the sustainability report should explain the reasons (GRI, 2013 b). In the zone matrices method, the responsibility for judging the applicability of aspects should be assigned to senior decision makers, considering their experience within the company and their knowledge of the organizational structure and processes. Senior decision makers can also decide to consider further sector specific sustainability aspects, for instance, those proposed by the GRI supplementary disclosure guidelines for certain industrial sectors, such as food processing and electrical utilities (GRI, 2013c).

For all aspects considered relevant, the company then proceeds with the further steps of the method.

For ACMO, the selection of the relevant sustainability aspects was completed by the chair of the board of directors, who judged all GRI aspects in Table 1 as relevant. No further aspects have been added since water technology industry is not included in the GRI supplementary guidelines.

It is important to underline that materiality analysis can be exposed to "managerial capture": the opportunistic behaviour of the management involved in the process of materiality analysis, consisting in the strategic selection of information considered positive for the image of the company (Owen, Swift, Humphrey, \& Bowerman, 2000). To avoid this risk in the se- 


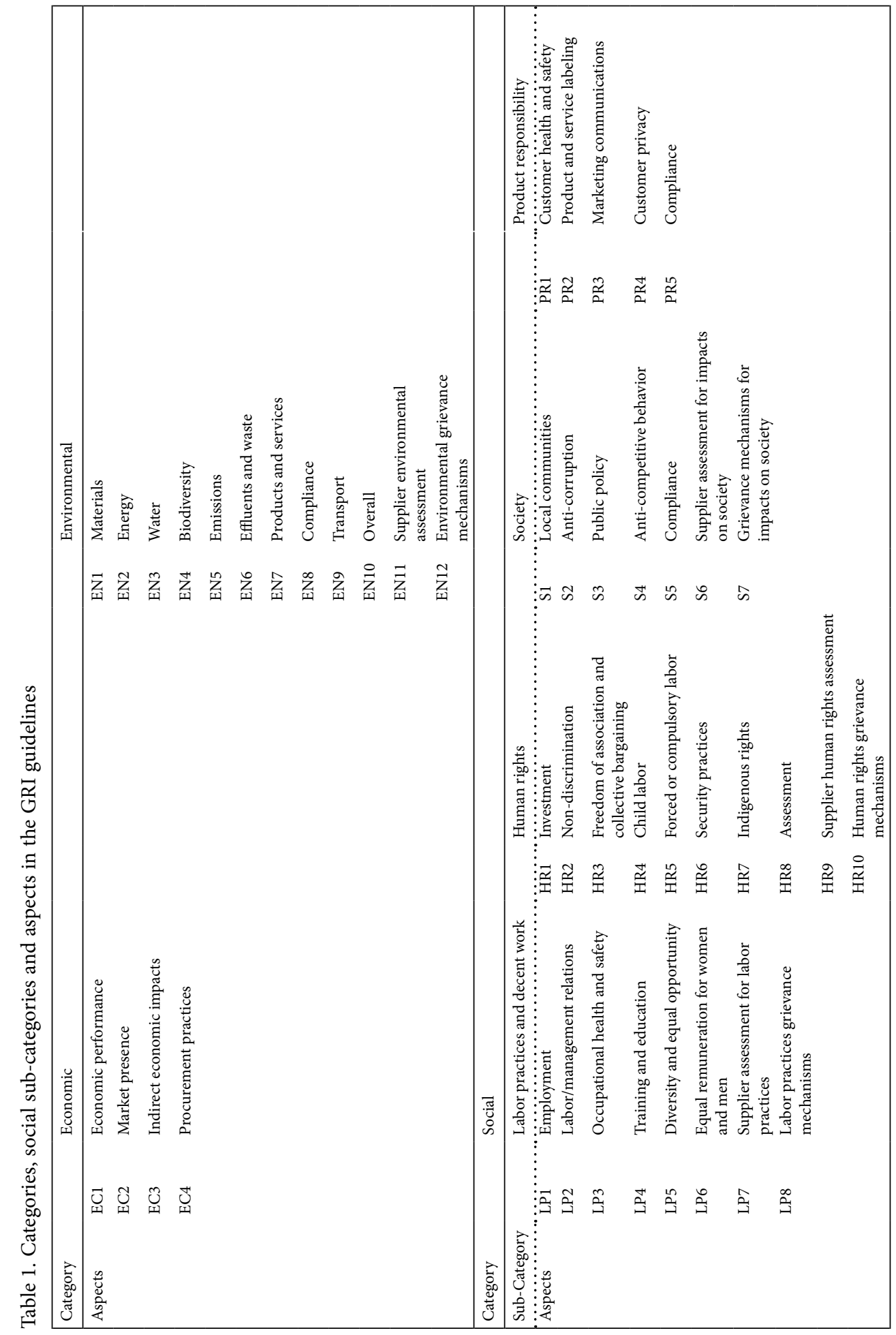


lection of the relevant sustainability aspects (as the exclusion of some sustainability aspects), GRI guidelines suggest involving stakeholders in the process and require providing detailed reasons for omissions in the sustainability report (GRI, 2013b).

\section{Step 3: Data gathering and consistency test}

In step 3, stakeholders and decision makers are asked to evaluate the importance (i.e. materiality) and adequacy of disclosure of the GRI sustainability aspects identified in step 2 .

While decision makers are usually knowledgeable about importance (and adequacy) of disclosure of sustainability issues, stakeholder engagement is likely to involve a broad variety of stakeholders with different levels of expertise and experience (AA, 2015). Moreover, there are many stakeholder engagement approaches (e.g. one-to-one meetings, focus groups, surveys, etc.) and, consequently, different techniques and methods that can be used to address different problems arising from data gathering (Krick, Forstater, Monaghan, \& Sillanpaa, 2005). Unbiased facilitators should guide stakeholders through a structured process of materiality assessment in order to explain the importance of the dimensions under analysis, informing without influencing them with their ideas on sustainability issues (Krick et al., 2005). To avoid this risk, it is preferable that a facilitator is an external and independent professional, who do not really have a stake in the outcomes of the materiality assessment. In the ACMO case, the authors performed as external facilitators and organized one-to-one meetings with each stakeholder and decision maker.

Both decision makers and stakeholders are asked to compare GRI aspects in groups, according to the GRI categories and subcategories (Table 1). Given the complexity of sustainability issues, some contradictions could emerge during the assessment procedure, making judgments inconsistent (Calabrese et al., 2016). These judgments must be checked for internal consistency, to prevent contradictions from affecting the evaluation process arising from uncertainty, vagueness or subjectivity (Yan \& Ma, 2015). The approach proposed for this step is based on the Spearman's correlation coefficient for trend detection (Gauthier, 2001) applied to the ordinal and interval rankings of the different aspects, for both importance and adequacy (van Calker, Berentsen, Giesen, \& Huirne, 2005). The interval ranking is derived from the importance (adequacy) indicated by the respondents for each GRI sustainability aspect. The respondents judge importance on a six-point Likert scale, from 1 for "no importance" to 6 for "very high importance". Disclosure adequacy is judged on a six-point Likert scale with 1 for "completely inadequate" to 6 for "very high adequacy". The respondents are then asked to indicate the sustainability aspects in order of importance (adequacy), expressing their answers as ordinal rankings.

The Spearman rank correlation coefficient between ordinal ranking and interval ranking of importance (adequacy) is then calculated (Gauthier, 2001; van Calker et al., 2005). The coefficient is compared to a critical value, which depends on the number of evaluated aspects (Zar, 1972). If the absolute value of the Spearman coefficient is larger than a critical value (corresponding to a level of significance), then the correlation between the ordinal and interval rankings is significant. The correlation between rankings implies the consistency of judgments (van Calker et al., 2005). If the correlation between the ordinal and interval rankings is not significant, the respondents must reconsider their answers and provide new judgments until consistency is achieved. 
In the ACMO application, all judgments were consistent with a confidence level of significance equal to $95 \%$.

\section{Step 4: Positioning of sustainability aspects in the zone matrices}

In Step 4, the different sustainability aspects are positioned within the zone matrices, serving to distinguish "material aspects", "not material" aspects, and "emerging issues", in keeping with the GRI definitions. An aspect is material if it is sufficiently important in reflecting the company's impacts or the stakeholders' assessments and interests. The threshold level for "sufficient" importance (i.e. materiality) is set at the mid position between level 3 ("low importance") and level 4, ("important"), of the Likert scale. Once the threshold has been set, the different areas of materiality can be identified in the materiality matrix (Table 2): "materiality zone", "emerging materiality zone", "not material zone".

Similarly, the areas of the adequacy of the CS communication are determined (Table 3), as: "adequacy zone", "improving zone", "not adequacy zone".

The positioning of the aspects within the zone matrices derives from calculation of the weighted average values of importance and adequacy, for both stakeholders and decision makers. Relative weights should be assigned to the different respondents, according to their relevance in the decisional process. Indeed, decision makers and stakeholders' perceptions are both of crucial importance for capturing the cause-effect dynamics of the company's value creation process (Rossi, Cricelli, Grimaldi, \& Greco, 2006). Therefore, the identification of the relative weights of each respondent must reflect her/his knowledge of the company and its operational contexts, and her/his know-how and experience concerning the GRI aspect under analysis. The identification of these relative weights is of fundamental importance for achieving effective multi-stakeholder contributions to the materiality analysis. For this reason, the weights should be attributed by the company's senior executives, meaning top ranking members of the company management, such as the Chief Executive Officer (CEO) and individuals reporting directly to the CEO (GRI, 2013b). Senior executives have a deep understanding of the company's organizational structure, processes, and resource, and can effectively contribute to design a participatory assessment approach to the reporting decisions.

Each participating stakeholder and decision maker must be assigned specific weights for the different sustainability dimensions. In addition, the weights assigned to a respondent for judging importance of GRI aspects can be different from those assigned to judge adequacy of GRI aspects.

In the ACMO example, the $\mathrm{CEO}$ assigned different weights for the different categories of stakeholders and decision makers. In particular, for each sustainability dimension, the CEO assigned to each category of stakeholders and decision makers a specific weight relative to the "importance" assessment of GRI aspects, that was different from the weight assigned for the "adequacy" assessment. As an example, each decision maker was assigned an identical weight of $20 \%$ to evaluate the "adequacy" of GRI economic aspects (Table 1), while they were assigned different weights to judge the "importance": $35 \%$ to the chair of the board of directors and to the CEO, and $10 \%$ to each manager (production manager, design manager and quality system manager).

The resulting matrices are shown in Figures 1 and 2. 

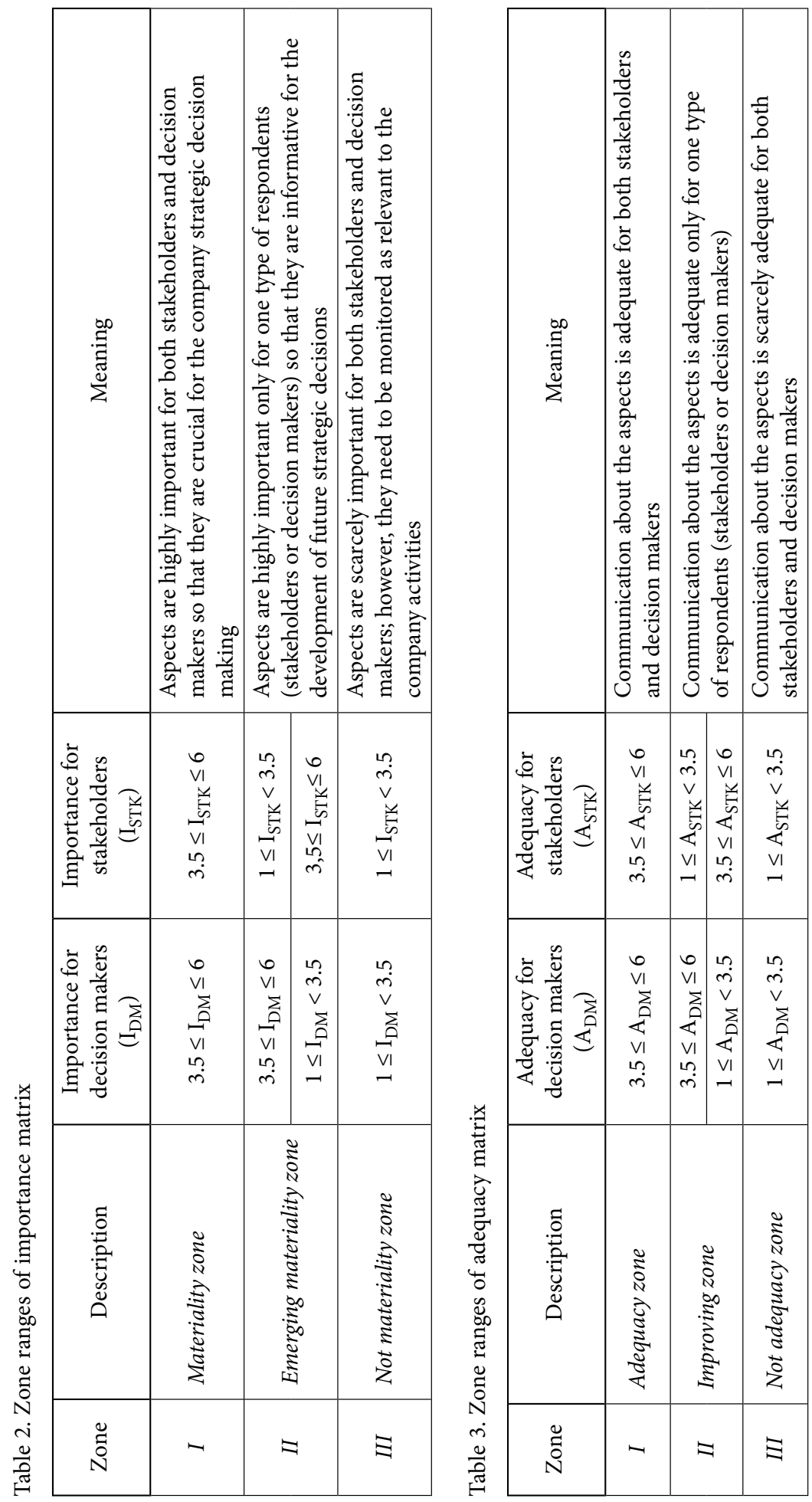


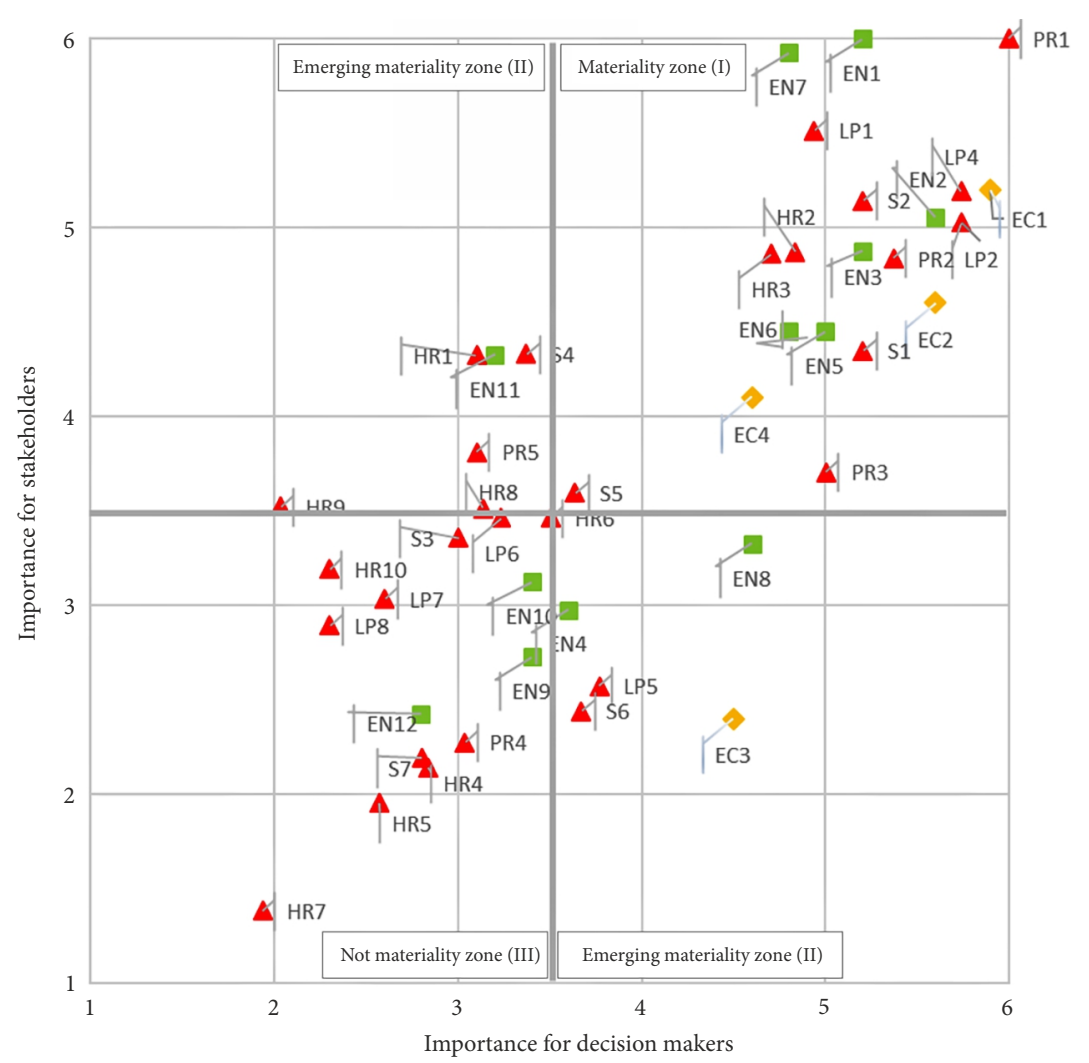

Economic aspects

Environmental aspects

A Social aspects

Figure 1. ACMO's materiality matrix

For the ACMO example, economic aspects EC1, EC2 and EC4 (materiality matrix zone I) are identified as having high importance to both stakeholders and decision makers. Aspect EC3 (concerning indirect economic impacts) is identified as having emerging materiality (zone II), since it is perceived as important only by decision makers. However, such aspects could become more relevant, may indicate strategic opportunities, and according to the GRI guidelines cannot be neglected. Companies should thus also provide disclosure for aspects identified as "emerging".

Most of the environmental aspects are also highly important; only three of these aspects (EN9, EN10 and EN12) are situated in zone III (not material). Among the social aspects, those relating to product responsibility are more important, while those relating to human rights are less important. These results are consistent with the fact that ACMO's business activities are concentrated in Europe, where respect for human rights is quite well achieved and likely not at the forefront of attention, in this particular industrial sector. Different results could be expected in other global jurisdictions or in other sectors.

Concerning disclosure activities, communications regarding product responsibility aspects are evaluated as more adequate (i.e. for PR1 - customer health and safety, and PR2 product and service labelling): these place in zone I of the adequacy matrix. These results are consistent with the fact that ACMO places heavy emphasis on CS communication of 


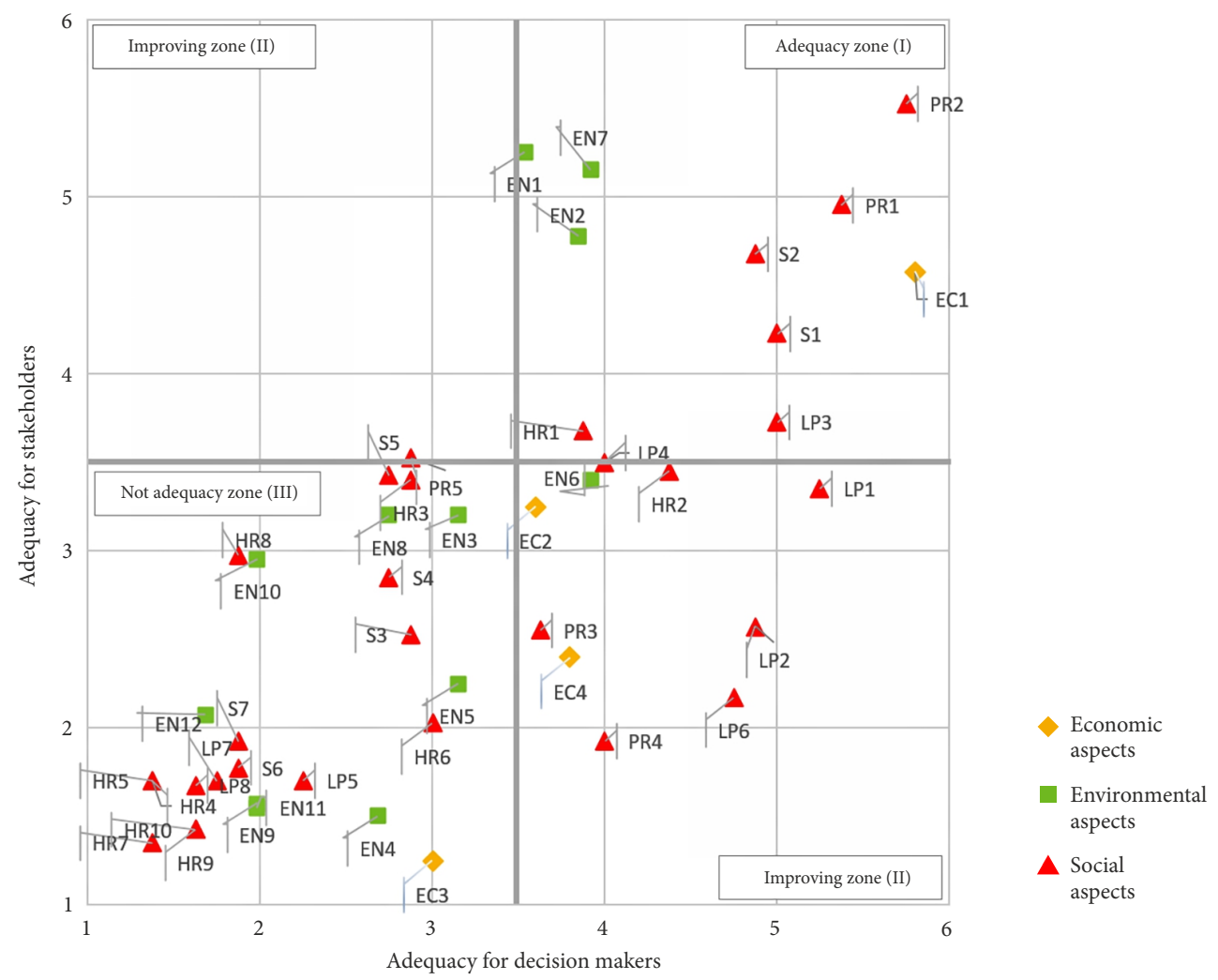

Figure 2. ACMO’s adequacy matrix

product innovativeness, through national and international trade fairs, the company website and use of social media. Finally, the zone matrices approach provides the important observation that CS communications concerning material environmental aspects are perceived as scarcely adequate, suggesting that, although ACMO has achieved the ISO 14001 certification for its environmental management system, specific CS communications would be required in this regard.

\section{Step 5: Prioritizing sustainability aspects}

At this point, the relative priorities for reporting on the different aspects are calculated by combining their positions within the materiality and adequacy zones of matrices (Figures 1 and 2), for both stakeholders and decision makers. The company can then plan CS rationally, assigning greater priority to those aspects characterized by both high importance (i.e. materiality) and poor adequacy of CS communication. Table 4 shows the priority of reporting levels and overall results for the ACMO example.

The comparison between the positioning of each sustainability aspect in the two matrices shows the alignment between the effectiveness of CS communication (level of adequacy) and the strategic importance of the aspect (level of materiality). 
Table 4. Priority levels and results for decision makers (DM), stakeholders (STK), and overall in the ACMO application

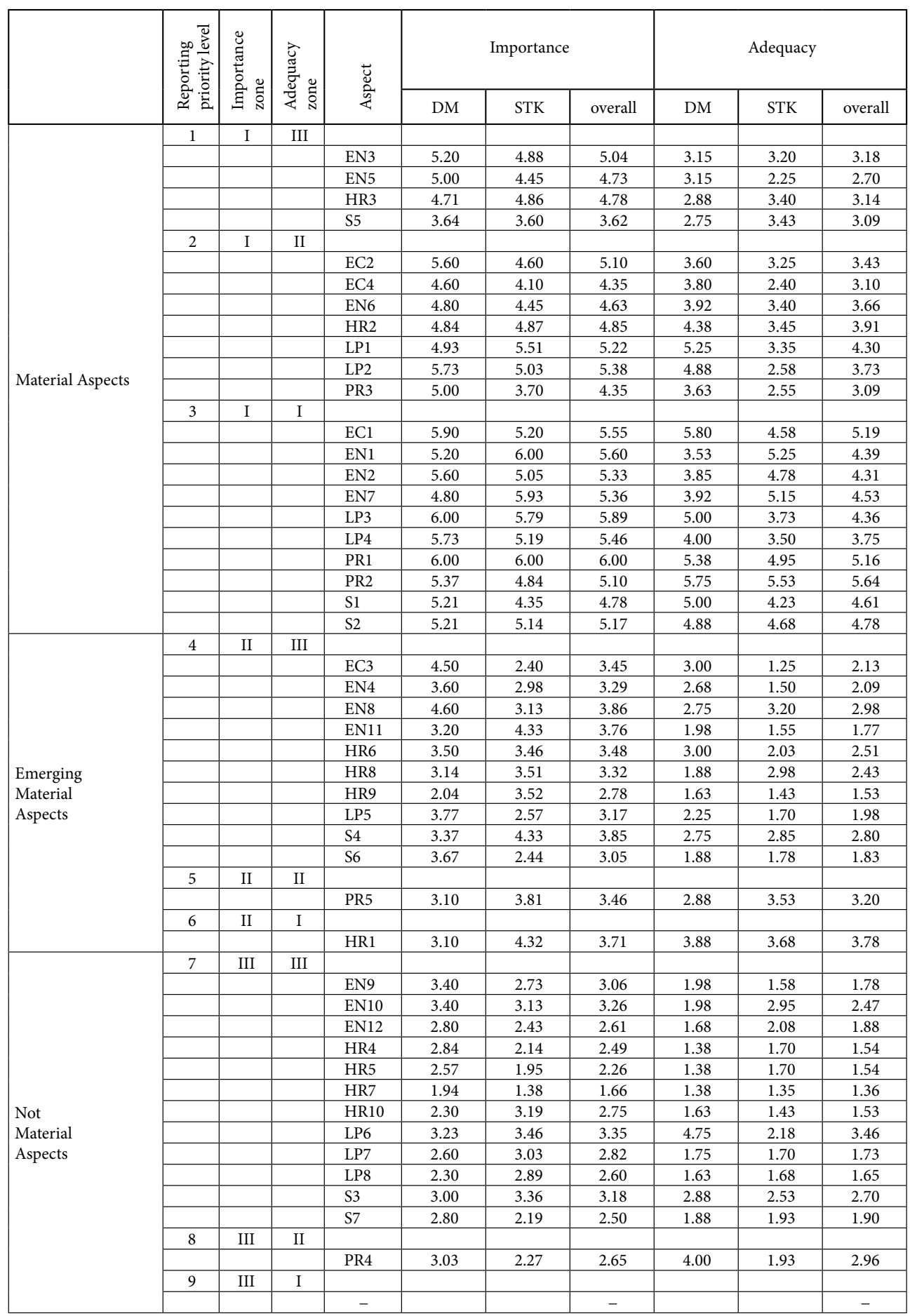


In the ACMO case, it is interesting to note that most of the aspects judged as material (zone I of the materiality matrix), appear to be also adequately communicated (zone I of the adequacy matrix). Nevertheless, some material aspects appear to be poorly communicated. Among them, the stakeholders judged the CS communication on emissions (EN5) as inadequate (value 2.25). A considerable number of sustainability aspects resulted as "emerging issues", and most of these were perceived to be inadequately communicated. Based on these results, the company using the zone matrices procedure (in this case ACMO) can identify the aspects that should be included in future sustainability reporting activities. The company can design its sustainability data collection and reporting to provide sufficiently detailed information on all material and emerging aspects, thereby improving accountability to stakeholders. The next step provides guidelines to this end.

\section{Step 6: Managerial implications}

Using the materiality and adequacy matrices produced in Step 5, the company can next draw up a table identifying the required levels of coverage in preparing sustainability reporting (see Table 5). The combined utilization of the two matrices allows identifying material sustainability aspects that are not adequately communicated, enabling companies to enhance accountability to stakeholders. The "reporting priority levels" (Table 5, first column) are derived from the zone positioning in both the materiality and adequacy matrices, relatively tabulated in increasing and descending order (columns two and three). The "required level of coverage" (column 4) offers guidelines for target setting, monitoring and reporting, thereby allowing the company to identify areas for refocusing their CS communication efforts and improving accountability to stakeholders. Aspects characterized by lower levels of adequacy and higher levels of importance (i.e. materiality) are those where the company should devote greater effort to actions for improving company accountability. The proposed method considers three levels for refocusing the required communications coverage (high, medium, low), corresponding to the disclosure adequacy zones (zones III, II, I). The company can use these levels as criteria for allocating resources to CS activities. Especially in the case of companies with limited resources (as might be expected for SMEs), greater effectiveness could be achieved by rebalancing resource allocations, or by marginal increases for coverage of reporting in the appropriate areas. Table 5 exemplifies the kind of guidelines that can be developed for collecting information to be included in sustainability reporting, and in general in CS communication. In this case, column six "sustainability aspects" is specific to the ACMO example.

SMEs notoriously lack time, specialized knowledge and financial resources necessary for appropriate documentation of sustainability performance (Borga, Citterio, Noci, \& Pizzurno, 2009). Given this, it appears that the zone matrices method should be particularly suitable for SMEs, allowing them to concentrate reporting activities on "material" aspects that are communicated ineffectively, thus exceeding the time and financial constraints that SMEs often face in sustainability reports (Baumann-Pauly et al., 2013). For this reason, the zone matrices method should support sustainability reporting for many SMEs that can not yet afford formal and structured sustainability reports. For companies that are already engaged in sustainability reporting, the method helps to improve relevance and accuracy, while still containing costs in terms of time and resources. 
Table 5. Level of coverage for each reporting priority level

\begin{tabular}{|c|c|c|c|c|c|c|}
\hline & $\begin{array}{l}\text { Reporting } \\
\text { Priority } \\
\text { Level }\end{array}$ & $\begin{array}{c}\text { Zone } \\
\text { of } \\
\text { importance }\end{array}$ & $\begin{array}{l}\text { Zone } \\
\text { of } \\
\text { adequacy }\end{array}$ & Required level of coverage & $\begin{array}{c}\text { Sustainability } \\
\text { communication } \\
\text { effort }\end{array}$ & $\begin{array}{l}\text { Sustainability } \\
\text { aspects }\end{array}$ \\
\hline \multirow{3}{*}{$\begin{array}{l}\text { Material } \\
\text { aspects }\end{array}$} & 1 & I & III & \multirow{3}{*}{$\begin{array}{l}\text { Detailed sustainability performance } \\
\text { regarding: } \\
\text { - sustainability performance } \\
\text { indicators } \\
\text { - trend analysis } \\
\text { - methods and approaches used to } \\
\text { monitor performance } \\
\text { - linkage to business strategy } \\
\text { - how the impacts generated by } \\
\text { material aspects are managed } \\
\text { - target values to achieve }\end{array}$} & High & EN3; EN5; HR3; S5 \\
\hline & 2 & I & II & & Medium & $\begin{array}{l}\text { EC2; EC4; EN6; } \\
\text { HR2; LP1; LP2; PR3 }\end{array}$ \\
\hline & 3 & I & I & & Low & $\begin{array}{l}\text { EC1; EN1; EN2; } \\
\text { EN7; LP3; LP4; PR1; } \\
\text { PR2; S1; S2 }\end{array}$ \\
\hline \multirow{3}{*}{$\begin{array}{l}\text { Emerging } \\
\text { material } \\
\text { aspects }\end{array}$} & 4 & II & III & \multirow{3}{*}{$\begin{array}{l}\text { Sustainability performance } \\
\text { information regarding: } \\
\text { - performance indicators } \\
\text { - qualitative description of methods } \\
\text { and approaches used to monitor } \\
\text { performance } \\
\text { - how the impacts generated by } \\
\text { material aspects are managed } \\
\text { - future initiatives }\end{array}$} & High & $\begin{array}{l}\text { EC3; EN4; EN8; } \\
\text { EN11; HR6; HR8; } \\
\text { HR9; LP5; S4; S6 }\end{array}$ \\
\hline & 5 & II & II & & Medium & PR5 \\
\hline & 6 & II & I & & Low & HR1 \\
\hline \multirow{3}{*}{$\begin{array}{l}\text { Not } \\
\text { material } \\
\text { aspects }\end{array}$} & 7 & III & III & \multirow{3}{*}{$\begin{array}{l}\text { Description of reasons for which } \\
\text { aspects are relevant and need to be } \\
\text { monitored }\end{array}$} & High & $\begin{array}{l}\text { EN9; EN10; EN12; } \\
\text { HR4; HR5; HR7; } \\
\text { HR10; LP6; LP7; } \\
\text { LP8; S3; S7 }\end{array}$ \\
\hline & 8 & III & II & & Medium & PR4 \\
\hline & 9 & III & I & & Low & --- \\
\hline
\end{tabular}

For ACMO, the greatest effort for redirecting collection and reporting of information should go to aspects EN3, EN5, HR3 and S5. These aspects are crucial to the company's sustainability strategy and are of high interest for stakeholders (zone I of the materiality matrix), but at the same time, the adequacy of CS communications is low (zone III of the adequacy matrix). Companies observing such situations would require specific initiatives to improve accountability through reporting. For instance, regarding the aspect EN5 "emissions", sustainability reporting would clearly communicate both why that aspect is central to achievement of company strategic objectives, and important for both stakeholders and decision makers, and then explain how impacts related to this aspect are managed. Companies should also identify quantitative indicators for monitoring of sustainability performance and disclosure. Reporting should then indicate the values achieved in both current and previous periods, thereby revealing the trends in sustainability performance. Target values should be specified, along with the planned initiatives for their achievement. The GRI guidelines provide examples of such performance indicators, for example concerning aspect EN5 (emissions): "energy consumption within and outside the organization", "energy intensity", "reduction of energy consumption", "reductions in energy consumptions of products and services". Performance indicators should be identified for all material aspects (i.e. reporting priority levels of 1, 2 and 3 in Table 5). The company can invest proportionally in new efforts for collecting and reporting data: new or redirected resources should be assigned to specifically planned CS communication efforts concerning aspects with lowest adequacy. Using the proposed method, the company has classified the different aspects with respect to the required reporting efforts, and can now plan of resource allocations for the respective activities. 
The proposed method can be exceptionally useful to companies that are just beginning to engage in sustainability reporting (e.g. the case for ACMO). It supports the company in planning both data collection and disclosure activities, including the formal periodic sustainability report. The company is better able to identify those material aspects that are not adequately communicated, thereby planning improved CS recording and communications, and enhancing their accountability to stakeholders.

The proposed method also allows companies to identify which stakeholders harbor poorer perceptions, and consequently propose targeted CS communication initiatives. For example in the ACMO illustrative example, it is extremely important to target customer perceptions, in the area of health and safety (PR1). For this company, PR1 is a material aspect with high priority level (3) and, in fact, it is currently well communicated (zone I of the adequacy matrix, overall level 5.16). Company management has clearly recognized the importance of this aspect and has implemented useful CS communications through its different channels of reporting (website, brochures, trade fairs, etc). However, in spite of this generally good result, stakeholders give a slightly lower judgment of disclosure adequacy than do decision makers. This company could then achieve significant improvements through redirection of resources to new initiatives in CS communication, specifically targeting stakeholders on the matter of health and safety.

\section{Discussion and conclusions}

Through the investigation of stakeholder expectations, companies can identify new opportunities for improving both social and environmental sustainability and competitive advantage (Porter \& Kramer, 2006). In this sense, materiality analysis plays an important role in the creation of shared value. It serves in determining issues that are material for sustainability, and in prioritizing the different topics from the two perspectives of organizational strategy and stakeholder interests (Font et al., 2016). Materiality analysis can serve companies in integrating strategic decision making with corporate sustainability, in an approach where actions and reporting are aligned with current and emerging economic, environmental and social risks and opportunities (Forstater et al., 2006; Herzig \& Schaltegger, 2011).

Nevertheless, a review of the literature revealed that materiality analysis presents critical issues that limit its practical use in companies (Pérez-López et al., 2015; Calabrese et al., 2017). Materiality analysis is in fact a highly subjective process that requires mediating among potential conflicts, and dealing with uncertainty and consistency of judgments across a wide range of issues. However, few contributions have proposed a structured approach for materiality analysis, through which both stakeholders and decision makers can participate in defining the reporting content, and in evaluating the adequacy, effectiveness and transparency of the current reporting practices.

In response to these shortcomings, this paper proposes a new method for practical application of materiality analysis. Stakeholders and decision makers both participate in prioritizing sustainability aspects in terms of importance and adequacy of disclosure, through the use of zone matrices based on scaled rankings. "Materiality" and "adequacy" matrices are divided into zones, serving to identify materiality thresholds and relative priorities for reporting. 
A weighted average approach is proposed to handle subjectivity of assessment, mediating among the diverse and potentially conflicting stakeholders' judgments. The method includes a consistency test, overcoming the critical issue of discrepancies in judgements. Since transparency and completeness of report content constitute crucial challenges of sustainability reporting, the proposed method provides companies with guidance on the level of coverage, meaning the kind of information (narrative or quantitative) to structure sustainability reporting, based on the priority weights derived from the zone matrices. The comparison between materiality and adequacy of sustainability aspects supports rational planning of CS communication efforts, thus optimizing the company's allocation of resources for improvements in reporting and accountability.

The adequacy assessment of CS communication practices concerns sustainability reports, but it could also involve other forms of CS communication, such as company websites and social media, since the web has become one the predominant communication channel for sustainability initiatives, reshaping CS communication and effective stakeholder engagement (Nwagbara \& Reid, 2013; Lindgreen \& Swaen, 2010).

The paper illustrates the application of the method through the example of an Italian SME operating in the water technology industry. The illustration demonstrates the particular utility of the method for companies that are just beginning to engage in planned disclosure, including the traditional sustainability report. The method is particularly useful for small to medium enterprises, facing constraints on resources and capacity, but it is also indicated to large companies of any sector since it supports materiality analysis by means of a structured step-by-step approach.

Future studies should investigate how the "zone matrices" method for materiality analysis could be used to develop new and improved approaches in sustainability reporting, such as in discerning the differences in the perceptions of the different kinds of stakeholders and decision makers concerning CS importance and effectiveness of disclosure. The results could then be used to support improved accountability for these various audiences.

\section{Author contributions}

The authors contributed equally and are listed in alphabetical order.

\section{Acknowledgements}

We thank the reviewers whose comments improved the initial version of this manuscript. We especially thank Paolo Sebastiani (ACMO’s president) and Costanza Sebastiani for their contribution in the realization of the illustrative application.

\section{References}

AccountAbility. (2015). AA1000 Stakeholder Engagement Standard. Retrieved from https://www.accountability.org/

AccountAbility. (2018). AA1000 Accountability Principles. Retrieved from https://www.accountability.org/ 
Alonso, J. A., \& Lamata, M. T. (2006). Consistency in the analytic hierarchy process: a new approach. International Journal of Uncertainty, Fuzziness and Knowledge-Based Systems, 14(04), 445-459. https://doi.org/10.1142/S0218488506004114

Andriof, J., Waddock, S., Husted, B., \& Rahman, S. S. (2017). Unfolding stakeholder thinking: theory, responsibility and engagement. Routledge: New York. https://doi.org/10.4324/9781351281843

Ascough, J. C., Maier, H. R., Ravalico, J. K., \& Strudley, M. W. (2008). Future research challenges for incorporation of uncertainty in environmental and ecological decision-making. Ecological Modelling, 219(3), 383-399. https://doi.org/10.1016/j.ecolmodel.2008.07.015

Baumann-Pauly, D., Wickert, C., Spence, L. J., \& Scherer, A. G. (2013). Organizing corporate social responsibility in small and large firms: size matters. Journal of Business Ethics, 115(4), 693-705. https://doi.org/10.1007/s10551-013-1827-7

Bellantuono, N., Pontrandolfo, P., \& Scozzi, B. (2016). Capturing the stakeholders' view in sustainability reporting: a novel approach. Sustainability, 8(4), 1-12. https://doi.org/10.3390/su8040379

Borga, F., Citterio, A., Noci, G., \& Pizzurno, E. (2009). Sustainability report in small enterprises: case studies in Italian furniture companies. Business Strategy and the Environment, 18(3), 162-176. https://doi.org/10.1002/bse.561

Bowers, T. (2010). From image to economic value: a genre analysis of sustainability reporting. Corporate Communications: an International Journal, 15(3), 249-262. https://doi.org/10.1108/13563281011068113

Byrne, D. M., Lohman, H. A., Cook, S. M., Peters, G. M., \& Guest, J. S. (2017). Life cycle assessment (LCA) of urban water infrastructure: emerging approaches to balance objectives and inform comprehensive decision-making. Environmental Science: Water Research \& Technology, 3(6), 1002-1014. https://doi.org/10.1039/C7EW00175D

Calabrese, A., Costa, R., Levialdi, N., \& Menichini, T. (2019). Integrating sustainability into strategic decision-making: A fuzzy AHP method for the selection of relevant sustainability issues. Technological Forecasting and Social Change, 139, 155-168. https://doi.org/10.1016/j.techfore.2018.11.005

Calabrese, A., Costa, R., Ghiron, N. L., \& Menichini, T. (2017). Materiality analysis in sustainability reporting: a method for making it work in practice. European Journal of Sustainable Development, 6(3), 439-447. https://doi.org/10.14207/ejsd.2017.v6n3p439

Calabrese, A., Costa, R., Levialdi, N., \& Menichini, T. (2016). A fuzzy Analytic Hierarchy Process method to support materiality assessment in sustainability reporting. Journal of Cleaner Production, 121, 248-264. https://doi.org/10.1016/j.jclepro.2015.12.005

Calace, D. (2016). Battle of Giants: GRI vs SASB vs IR. GreenBiz. Retrieved from https://www.greenbiz. com/article/battle-giants-gri-vs-sasb-vs-ir

Carpejani, P., Pinheiro de Lima, E., Gouvea da Costa, S. E., Machado, C. G., \& Da Veiga, C. P. (2017). The contribution of the process of materiality to the evolution of the field of sustainability performance measurement. Paper presented at the Proceedings of the International Joint Conference - ICIEOMADINGOR-IISE-AIM-ASEM (IJC 2017). https://doi.org/10.12783/dtetr/icpr2017/17688

Costa, R., \& Menichini, T. (2013). A multidimensional approach for CSR assessment: the importance of the stakeholder perception. Expert Systems with Applications, 40(1), 150-161. https://doi.org/10.1016/j.eswa.2012.07.028

Crane, A., \& Livesey, S. (2003). Are you talking to me? Stakeholder communication and the risks and rewards of dialogue. In J. Andriof, S. Waddock, B. Husted, \& S. S. Rhaman (Eds.), Unfolding stakeholder thinking 2. Relationships, communication, reporting and performance (pp. 39-52). Sheffield: Greenleaf. https://doi.org/10.9774/GLEAF.978-1-909493-32-2_4

Da Giau, A., Macchion, L., Caniato, F., Caridi, M., Danese, P., Rinaldi, R., \& Vinelli, A. (2016). Sustainability practices and web-based communication: an analysis of the Italian fashion industry. Journal of Fashion Marketing and Management, 20(1), 72-88. https://doi.org/10.1108/JFMM-07-2015-0061 
Dwyer, S., Richard, O. C., \& Chadwick, K. (2003). Gender diversity in management and firm performance: the influence of growth orientation and organizational culture. Journal of Business Research, 56(12), 1009-1019. https://doi.org/10.1016/S0148-2963(01)00329-0

Edgley, C. (2014). A genealogy of accounting materiality. Critical Perspectives on Accounting, 25(3), 255-271. https://doi.org/10.1016/j.cpa.2013.06.001

Elias, A. A., Jackson, L. S., \& Cavana, R. Y. (2004). Changing positions and interests of stakeholders in environmental conflict: a New Zealand transport infrastructure case. Asia Pacific Viewpoint, 45(1), 87-104. https://doi.org/10.1111/j.1467-8376.2004.00229.x

Font, X., Guix, M., \& Bonilla-Priego, M. J. (2016). Corporate social responsibility in cruising: using materiality analysis to create shared value. Tourism Management, 53, 175-186. https://doi.org/10.1016/j.tourman.2015.10.007

Forstater, M., Zadek, S., Evans, D., Knight, A., Sillanpaa, M., Tuppen, C., \& Warris, A. (2006, November). The materiality report: aligning strategy, performance and reporting. London: AccountAbility.

Gauthier, T. D. (2001). Detecting trends using Spearman's rank correlation coefficient. Environmental Forensics, 2(4), 359-362. https://doi.org/10.1006/enfo.2001.0061

Greenwood, M. (2007). Stakeholder engagement: beyond the myth of corporate responsibility. Journal of Business Ethics, 74, 315-327. https://doi.org/10.1007/s10551-007-9509-y

Global Reporting Initiative. (2013a). G4, Part 1, reporting principles and standard disclosure. Retrieved from https://www.globalreporting.org/resourcelibrary/GRIG4-Part1-Reporting-Principles-andStandard-Disclosures.pdf

Global Reporting Initiative. (2013b). G4, Part 2, implementation manual. Retrieved from https://www.globalreporting.org/resourcelibrary/GRIG4-Part2-Implementation-Manual.pdf

Global Reporting Initiative. (2013c). G4, sector disclosures. Retrieved from https://www.globalreporting. org/information/g4/sector-guidance/sectorguidanceG4/Pages/default.aspx

Global Reporting Initiative. (2016). Consolidated set of GRI sustainability reporting standards. Retrieved from https://www.globalreporting.org/standards/gri-standards-download-center/consolidated-setof-gri-standards/

Guix, M., Bonilla-Priego, M. J., \& Font, X. (2018). The process of sustainability reporting in international hotel groups: an analysis of stakeholder inclusiveness, materiality and responsiveness. Journal of Sustainable Tourism, 26(7), 1063-1084. https://doi.org/10.1080/09669582.2017.1410164

Hahn, R., \& Kühnen, M. (2013). Determinants of sustainability reporting: a review of results, trends, theory, and opportunities in an expanding field of research. Journal of Cleaner Production, 59, 5-21. https://doi.org/10.1016/j.jclepro.2013.07.005

Harrison, J., \& Wicks, A. (2013). Stakeholder theory, value, and firm performance. Business Ethics Quarterly, 23(1), 97-124. https://doi.org/10.5840/beq20132314

Hellström, D., Jeppsson, U., \& Kärrman, E. (2000). A framework for systems analysis of sustainable urban water management. Environmental Impact Assessment Review, 20(3), 311-321. https://doi.org/10.1016/S0195-9255(00)00043-3

Herzig, C., \&Schaltegger, S. (2011). Corporate sustainability reporting. In Sustainability communication (pp. 151-169). Springer Netherlands. https://doi.org/10.1007/978-94-007-1697-1_14

Hsu, C. W., Lee, W. H., \& Chao, W. C. (2013). Materiality analysis model in sustainability reporting: a case study at Lite-On Technology Corporation. Journal of Cleaner Production, 57, 142-151. https://doi.org/10.1016/j.jclepro.2013.05.040

International Organization for Standardization. (2010). Guidance on Social Responsibility (ISO 26000:2010(E)). Geneva, Switherland. 
Jones, P., Comfort, D., \& Hillier, D. (2016). Managing materiality: a preliminary examination of the adoption of the new GRI G4 guidelines on materiality within the business community. Journal of Public Affairs, 16(3), 222-230. https://doi.org/10.1002/pa.1586

Krick, T., Forstater, M., Monaghan, P., \& Sillanpaa, M. (2005). The stakeholder engagement manual volume 2: the practitioners handbook on stakeholder engagement. AccountAbility, the United Nations Environment Programme, and Stakeholder Research Associates.

Landrum, N. E., \& Ohsowski, B. (2018). Identifying worldviews on corporate sustainability: a content analysis of corporate sustainability reports. Business Strategy and the Environment, 27(1), 128-151. https://doi.org/10.1002/bse.1989

Lindgreen, A., \& Swaen, V. (2010). Corporate social responsibility. International Journal of Management Reviews, 12(1), 1-7. https://doi.org/10.1111/j.1468-2370.2009.00277.x

Mahgoub, M. E. S. M., van der Steen, N. P., Abu-Zeid, K., \& Vairavamoorthy, K. (2010). Towards sustainability in urban water: a life cycle analysis of the urban water system of Alexandria City, Egypt. Journal of Cleaner Production, 18(10), 1100-1106. https://doi.org/10.1016/j.jclepro.2010.02.009

Manetti, G. (2011). The quality of stakeholder engagement in sustainability reporting: empirical evidence and critical points. Corporate Social Responsibility and Environmental Management, 18(2), 110-122. https://doi.org/10.1002/csr.255

Messier Jr, W. F., Martinov-Bennie, N., \& Eilifsen, A. (2005). A review and integration of empirical research on materiality: Two decades later. Auditing: A Journal of Practice \& Theory, 24(2), 153-187. https://doi.org/10.2308/aud.2005.24.2.153

Milne, M., \& Gray, M. R. (2013). Towards reporting on the triple bottom line: mirages, methods and myths. In The triple bottom line: does it all add up (pp. 92-102). London: Routledge.

Muga, H. E., \& Mihelcic, J. R. (2008). Sustainability of wastewater treatment technologies. Journal of environmental management, 88(3), 437-447. https://doi.org/10.1016/j.jenvman.2007.03.008

Nwagbara, U., \& Reid, P. (2013). Corporate social responsibility communication in the age of new media: towards the logic of sustainability communication. Revista de Management Comparat International, 14(3), 400-414.

Owen, D. L., Swift, T. A., Humphrey, C., \& Bowerman, M. (2000). The new social audits: accountability, managerial capture or the agenda of social champions? European Accounting Review, 9(1), 81-98. https://doi.org/10.1080/096381800407950

Pérez-López, D., Moreno-Romero, A., \& Barkemeyer, R. (2015). Exploring the relationship between sustainability reporting and sustainability management practices. Business Strategy and the Environment, 24(8), 720-734. https://doi.org/10.1002/bse.1841

Porter, M. E., \& Kramer, M. R. (2006). Strategy and society: the link between competitive advantage and corporate social responsibility. Harvard Business Review, 84(12), 78-92.

Rossi, C., Cricelli, L., Grimaldi, M., \& Greco, M. (2016). The strategic assessment of intellectual capital assets: an application within Terradue Srl. Journal of Business Research, 69(5), 1598-1603. https://doi.org/10.1016/j.jbusres.2015.10.024

Russo-Spena, T., Tregua, M., \& De Chiara, A. (2016). Trends and drivers in CSR disclosure: a focus on reporting practices in the automotive industry. Journal of Business Ethics, 151(2), 563-578. https://doi.org/10.1007/s10551-016-3235-2

Salzmann, O., Ionescu-Somers, A., \& Steger, U. (2005). The business case for corporate sustainability: literature review and research options. European Management Journal, 23(1), 27-36. https://doi.org/10.1016/j.emj.2004.12.007

Silvestre, W. J., Antunes, P., \& Leal Filho, W. (2018). The corporate sustainability typology: analysing sustainability drivers and fostering sustainability at enterprises. Technological and Economic Development of Economy, 24(2), 513-533. https://doi.org/10.3846/20294913.2016.1213199 
Stenzel, P. L. (2010). Sustainability, the triple bottom line, and the global reporting initiative. Global Edge Business Review, 4(6), 1-2.

Unerman, J. (2007). Stakeholder engagement and dialogue. In J. Unerman, J. Bebbington, \& B. O’Dwyer (Eds.), Sustainability accounting and accountability (pp. 86-103). London: Routledge. https://doi.org/10.4324/NOE0415384889.ch5

Van Calker, K. J., Berentsen, P. B., Giesen, G. W., \& Huirne, R. B. (2005). Identifying and ranking attributes that determine sustainability in Dutch dairy farming. Agriculture and Human Values, 22(1), 53-63. https://doi.org/10.1007/s10460-004-7230-3

Whitehead, J. (2017). Prioritizing sustainability indicators: using materiality analysis to guide sustainability assessment and strategy. Business Strategy and the Environment, 26(3), 399-412. https://doi.org/10.1002/bse.1928

Yan, H. B., \& Ma, T. (2015). A group decision-making approach to uncertain quality function deployment based on fuzzy preference relation and fuzzy majority. European Journal of Operational Research, 241(3), 815-829. https://doi.org/10.1016/j.ejor.2014.09.017

Zar, J. H. (1972). Significance testing of the Spearman rank correlation coefficient. Journal of the American Statistical Association, 67(339), 578-580. https://doi.org/10.1080/01621459.1972.10481251

Zhou, Y. (2011, November). Materiality approach in sustainability reporting: applications, dilemmas, and challenges. In 1st World Sustainability Forum (Vol. 1). https://doi.org/10.3390/wsf-00548 